\title{
Exploring the Sources of Collective Effervescence: A Multilevel Study
}

\author{
Lasse Suonperä Liebst
}

\author{
University of Copenhagen
}

\begin{abstract}
Collective effervescence is assigned a key role in sociological theorizing on ritual and group processes, yet surprisingly little research has systematically measured the phenomenon and examined its sources. In addressing this research gap, the current article explores and compares several correlates of collective effervescence. The data included questionnaires and geospatial records of spatial setting and movement patterns recorded at a large music festival. Multilevel regression modeling was applied, and the strength of the estimated evidence was assessed with frequentist and Bayesian approaches. Results suggest that collective effervescence is a highly spatially clustered phenomenon that, in particular, is associated with the social-morphological feature of being in a crowd of people. The article discusses the implications of these results for sociological Durkheim scholarship as well as for festival-event studies.
\end{abstract}

Keywords: Émile Durkheim; collective effervescence; Interaction Ritual Theory; multilevel regression

Citation: Liebst, Lasse Suonperä. 2019. "Exploring the Sources of Collective Effervescence: A Multilevel Study." Sociological Science 6: 27-42.

Received: October 27, 2018

Accepted: November 25, 2018

Published: January 17, 2019

Editor(s): Jesper Sørensen, Gabriel Rossman

DOI: $10.15195 /$ v6.a2

Copyright: (C) 2019 The Author(s). This open-access article has been published under a Creative Commons Attribution License, which allows unrestricted use, distribution and reproduction, in any form, as long as the original author and source have been credited. (0)(1)
A key argument of the sociological study of micro-interaction is that social A emotions are the "glue" of solidarity and the "energy" mobilizing change and conflict (Collins 2004; Turner 2010). An early and now classic attempt to theorize these complementary emotional processes is Durkheim's ([1912] 1995) concept of "collective effervescence," describing how the affective arousal of an assembled crowd creates the potential for both social conformity and group-based agency (Pickering 1984; Swann et al. 2012). Given the prominent status of the concept within the tradition, there is a surprising dearth of systematic empirical observations of collective effervescence (Buehler 2012), particularly with respect to locating the potential sources of this phenomenon (Kearney 2018). This may reflect the prevalence of armchair scholarship and a focus on interpretive epistemologies as opposed to an objectivist and quantitative examination of cause-effect relationships. The dominance of an interpretative approach within this field of study, it should be noted, runs counter to Durkheim $(1982)$ and Collins's $(1983,1989)$ positivist ambition that collective emotions should be measured and explained.

The purpose of the current article is to statistically examine and contrast a number of plausible sources of collective effervescence. For this inquiry, it is initially helpful to distinguish between the overall types of mechanisms that may influence a group of individuals to act, feel, or think in a similar manner. This may be ascribed to how the group participants interact, who they are, or where the group is located-that is, interactional, compositional, and environmental factors, respectively (Hedström 2005). Traditionally, it is assumed that collective effervescence is an emergent property of focused face-to-face interactions, and the alternative environmental and compositional accounts are accordingly attributed less explanatory weight. However, given the lack of research on the underpinnings 
of collective effervescence, it remains empirically uncertain whether this focus is justified, and the current article is a step toward examining this question.

In reviewing the existing research on collective effervescence, the article devotes particular attention to Collins's (2004) Interaction Ritual (IR) Theory, which arguably is the most advanced explanatory account of collective effervescence to date (von Scheve 2011). Broadly speaking, IR theory may be described as a formalized synthesis of Durkheim's (1995) sociology of religion and Goffman's (1967) situational micro-sociology. The ambitious claim of the theory is that any social phenomenon-from micro-interactional encounters to macro-historical trends-can ultimately be accounted for in terms of interaction ritual chains, comprising just a few ingredients (Collins 1981, 2004). These ingredients include a number of copresent individuals, physically gathered in a demarcated place, sharing a common mood and focus of attention. These variables are further reinforced through bodily processes of rhythmic entrainment by which participants become synchronized with each other's motions and emotions. This leads to an "intensification of shared experience, what Durkheim called collective effervescence, and the formation of collective conscience or collective consciousness" (Collins 2004:35). The subsequent ritual outcomes are the building of emotional energy in the individual combined with the growth of group solidarity, morality, and membership symbols.

From this outline of IR theory, we see that collective effervescence is mainly accounted for in terms of an interactional effect-the underpinning mechanism assumed is an "emotional contagion," by which the interacting participants influence and intensify each other's emotional state (Collins 2004; Heinskou and Liebst 2016). The empirical evidence supporting this interactional explanation is substantial and found across diverse social contexts, including harp singing (Heider and Warner 2010), restorative justice conferences (Rossner 2011), and even online discussion forums (DiMaggio et al. 2018). Adding to this, Collins's assumption regarding rhythmic entrainment as a basis for collective effervescence is neurologically plausible (Heinskou and Liebst 2016) and in line with meta-analytical evidence that interpersonal synchrony increases perceived social bonding and positive affect (Mogan, Fischer, and Bulbulia 2017).

A notable feature of the scholarly tradition theorizing collective effervescence is a dismissal of person-centered, compositional explanations. This is reflected in Durkheim's (1982) antipsychological stance, which prepared the ground for micro-sociological situationalism, as Goffman (1967:2-3) famously summarized: "Not, then, men and their moments. Rather moments and their men." The issues of placing a strong emphasis on the structural aspects of social life are well known (Smith 2015; Wrong 1961). Collins accepts Goffman's Durkheimian situationalism overall, but he also makes concessions to the critics of this position by including compositional elements into IR theory (Collins 1993). Specifically, he suggests that individuals tend to select themselves into interactions rituals, which "match up" with their cultural capital and emotional energy. If the person and situation mismatch, "the interaction ritual does not reach a high level of intensity, and the EE [emotional energy] payoff is low. Individuals are motivated to move away from such interactions" (Collins 2004:151). The level of collective effervescence and the corresponding individual experience of emotional energy are accordingly mediated 
by who is participating in the ritual. Such a compositional effect is consistent with the homophily principle, which holds that many group similarities, including plausibly emotional moods (Greetham et al. 2015), are a result of individuals associating with similar others (McPherson, Smith-Lovin, and Cook 2001).

Within Durkheimian studies (e.g., Alexander 2005), it is often argued that Durkheim's late sociology of religion signified a break from his earlier view that social life is shaped by environmental features, such as social density and physical space (referred to by Durkheim [1994] as the "social morphology"). This interpretation of Durkheim is questionable, however, given that it neglects the morphological insights found in his late sociology of religion and which subsequently informed Goffman and Collins's micro-sociology (Collins 1994, 2005; Liebst 2016). As such, Collins's $(2004: 53,81)$ argument that human "bodies moving into the same place starts off the ritual process," because there is "minimal excitement of being within a mass of human bodies," is aligned with the Durkheimian morphological view that spatially dense gatherings underpin the emergence of collective effervescence. This further resonates with Goffman's (1963) subsequent notion of "unfocused interaction," whereby it is the social density condition of mere copresence (without the need for direct "focused interaction") that influences the social ritual outcomes. Whether higher social densities facilitate positive emotions-or, alternatively, negative ones-is likely dependent on where the density occurs and thus on expectations and the existing emotions of the ritual site (Freedman 1975; Turner 2010).

Adding to the above considerations on the link between social density and collective emotions, some Durkheimian scholars have suggested that physical space may play a role in bringing the ritual gatherings into being. In an early study of the social morphology of the Inuit culture, Mauss ([1906] 1979) suggested that seasonal variation between the dense and dispersed living conditions during winter and summer, respectively, is associated with inverse levels of collective effervescence: "Winter is a season when Eskimo society is highly concentrated and in a state of continual excitement and hyperactivity" (Mauss 1979:76). Note that Mauss's link between social morphology and what would later be coined "collective effervescence" may have been influential for the formulation of the latter concept within the Durkheimian tradition (Pickering 1984). Further, in line with Mauss's argument, Durkheimian scholars have more recently shown that architectural morphological space may promote unequal density patterns of copresence, which in turn creates varying opportunities for micro-interactional encounters (Hillier et al. 1987; Liebst 2016).

Taken together, it is plausible that collective effervescence has several sources: interactional, compositional, and environmental. Besides focused interaction processes, which are common within Durkheimian research, the emotional intensity of rituals may also be shaped by the morphological level of unfocused crowd interaction and by social sorting, whereby individuals partake in interaction rituals that match their cultural capital and emotional energy. 


\section{Methods}

Data included a survey of randomly selected festival-goers attending Northern Europe's largest music festival, the Roskilde Festival, in 2011 (replication data and scripts are available as supplemental material at osf.io/eqdgb). The survey was sampled by a team of 11 university students during the five warm-up days of the festival, which precede the scheduled music program. During this period, tens of thousands of visitors build tent camps and engage in extensive drinking and partying activities. As such, the festival offered a "natural laboratory" (Park 1939) to examine the factors underpinning the collective effervescence that prior studies have identified in this (Pedersen 2014) and similar festival contexts (Niekrenz 2014). Specifically, the survey was conducted with face-to-face interviews in the interviewees' tent camps, allowing for a subsequent georeferring of data. Across 50 tent-camp locations, 505 responses were sampled with a response rate of 96 percent.

\section{Measures}

Dependent variable. Collective effervescence was measured as an additive index, with five items capturing the emotionally exalted aspects of dancing, animated movement, and noise-making that may be considered cues of the phenomenon (Collins 2007; see Table 1 for descriptive statistics of measures). Accordingly, the respondents were asked a battery of questions on how they experienced the immediate surroundings of their camps: "My camp is situated in a 'festive,' 'noisy,' 'hectic,' 'boring,' or 'calm' place." The response categories were "agree strongly," "agree," "disagree," and "disagree strongly" (note that the variables regarding boredom and calmness were reverse coded). The internal consistency of the constructed collective effervescence index was assessed to be high, with a Cronbach's alpha value of 0.83 . In order to obtain results with a comparable effect-size metric, the index was $z$-standardized prior to analysis.

Independent variables. The level of focused interaction was captured with the following question: "My camp hangs out a lot with neighboring camps," with a four-point Likert scale of the responses "agree strongly," "agree," "disagree," and "disagree strongly." This variable was included as a binary predictor with the two disagreeing responses as the reference category. Further, several predictors were included as measures of compositional features. Party preference, indexing the cultural capital and related emotional energy of the respondents, was captured with the following question: "It makes my festival experience greater if my camp is located in an area in which people are partying intensively." The four-point Likert scale responses "agree strongly," "agree," "disagree," and "disagree strongly" were coded into a binary predictor with the two disagreeing responses as the reference. Gender (female as the reference) and age (measured as an interval) were included in light of earlier research suggesting that these factors may influence how individuals engage in party and drinking events (Wilsnack et al. 2000). Finally, a continuous measure capturing the visitors' prior attendance at the festival was included: "How many times have you attended the Roskilde Festival prior to this year?" This variable was included as the visitors' previous attendance may influence how the festival spectacle is perceived, as is reflected in the well-known habituation process 
Table 1: Descriptive statistics.

\begin{tabular}{|c|c|c|c|c|}
\hline & Mean & $\begin{array}{l}\text { Standard } \\
\text { Deviation }\end{array}$ & Minimum & Maximum \\
\hline Collective effervescence & 10.09 & 2.85 & 1 & 16 \\
\hline Collective effervescence $\left(\right.$ standardized $^{\dagger}$ ) & 0.00 & 1.00 & -3.19 & 2.08 \\
\hline Focused interaction & 0.57 & 0.50 & 0 & 1 \\
\hline Party preference & 0.76 & 0.43 & 0 & 1 \\
\hline Male & 0.45 & 0.50 & 0 & 1 \\
\hline Age & 20.85 & 3.96 & 15 & 38 \\
\hline Age (standardized*) & -0.01 & 0.49 & -0.74 & 2.13 \\
\hline Prior attendance & 2.60 & 3.09 & 0 & 19 \\
\hline Social density & 3.50 & 0.47 & 2.30 & 4.19 \\
\hline Social density (standardized*) & 0.00 & 0.49 & -1.24 & 0.72 \\
\hline Centrality & $1,362.68$ & 446.46 & 645.83 & $2,408.28$ \\
\hline Centrality (standardized*) & -0.01 & 0.49 & -0.80 & 1.15 \\
\hline Spatial lag of collective effervescence & 9.29 & 2.04 & 4.1 & 13.3 \\
\hline $\begin{array}{l}\text { Spatial lag of collective effervescence } \\
\text { (standardized*) }\end{array}$ & 0.00 & 0.49 & -1.24 & 0.96 \\
\hline
\end{tabular}

Note. $N=469$, with an average of 9.4 (minimum $=5$; maximum $=19$ ) respondents nested across 50 contexts. The ambition was to sample 10 respondents per context. However, some contexts were so sparsely populated that this number could not be achieved in practice. Furthermore, in some contexts, we sampled beyond the desired number of respondents. This may reflect accidental oversampling or that some survey responses obtained in an adjacent context were mistakenly georeferenced. However, overall and given the limited occurrence of these issues, this should be considered a negligible source of bias.

$\dagger z$-standardized; $*$ Standardized by subtracting the mean and dividing by two standard deviations (Gelman 2008).

by which emotional arousal decreases with additional event exposure (Rankin et al. 2009).

The social-morphological factor of social density was captured with spatial network analysis tools—specifically, the "space syntax" method (Hillier and Raford 2010), which was used to create a proxy measurement of the level of movement or crowding density around the georeferenced tent contexts. The procedure involved the following steps. First, a high-resolution aerial photograph of the festival setting was converted into an axial map using the spatial network analysis tool UCL Depthmap (Turner 2004). This map depicts the fewest and longest lines needed to cover all the ways of moving around the layout (Hillier and Hanson 1984). Next, a segment angular choice analysis of the axial map was run. This choice analysis decomposed the axial lines into the segments between junctions and captured the shortest paths between all segments within a given metric radius-that is, the journey with the lowest angular cost for each possible origin and destination pair of segments (Turner 2001). In intuitive terms, a choice measure identifies the bridges that run across the network, representing movement-dense thoroughfares. Note that choice is equivalent to centrality betweenness (Freeman 1977), which is a well-known measure in sociological network analysis. 
Choice is important for the current analysis given that this network measure is a very strong predictor of movement densities in large-scale built environments (Hillier and Iida 2005; Sharmin and Kamruzzaman 2018). However, to assess whether choice is a valid proxy for real-life crowding patterns in the study context, the choice measurement was correlated with movement count data, which were collected in parallel with the survey data. Specifically, movement count data were recorded at 70 randomly localized gates, each of which was observed five to six times for three minutes (Griffiths 2014). A Spearman's correlation showed a strong positive association between movement and a local (approximate radius of 400 meters) choice measure $\left(r_{S}=0.74 ; p<0.01\right)$. As such, choice may be considered a valid proxy of movement or crowding density in this study setting. The social density predictor was calculated by taking the mean choice value of the path segments immediately surrounding each of the 50 locations where the georeferenced surveys were sampled. Note that all continuous independent variables were standardized by subtracting the mean and dividing by two standard deviations so as to make their estimates comparable to binary predictors (Gelman 2008).

As a final morphological predictor, the analysis included a measurement of the spatial centrality of the visitors' camp locations, which were captured as the beeline distance from each camp to the central music area. This variable was calculated in the geographic information system software MapInfo using the "place syntax" module (Ståhle, Marcus, and Karlström 2005). The basis for including this predictor is that research has long suggested that spatial centrality is a key aspect of built morphologies (Burgess 1925), including emplaced experiences (Snizek, Nielsen, and Skov-Petersen 2013). Finally, note that for transparency, the supplemental material includes all variables (osf.io/eqdgb), both those incorporated in the final analysis and those excluded after inspection.

\section{Estimation}

Data have a hierarchical structure, with visitor responses nested in festival locations, which violates the regression assumption of independence of observations (Musca et al. 2011). Multilevel modeling has been developed to correctly estimate such clustered data (Hox, Moerbeek, and van de Schoot 2017). The suitability of this approach was confirmed by calculating an intraclass correlation, which indicated that as much as 50 percent of the variance in the dependent variable is attributable to internally correlated differences between the clusters. Specifically, the article applied a two-level linear regression model with a random intercept, computed using Stata 14 's "mixed" module. Note that multilevel models are vulnerable to insufficient sample sizes. However, as suggested by McNeish and Stapleton (2016), as few as 30 contexts, containing an average of five individuals, yield unbiased fixed-effects point estimates in most modeling scenarios. With a mean of 9.4 individual-level records nested across 50 contexts, the data are comfortably within these bounds.

A potential limitation of using multilevel tools for spatial analysis is that the approach only offers a partial solution to the issue of spatial autocorrelation because the model ignores any dependencies between clusters. To assess this issue, a Moran's I statistic was calculated $(I=0.74 ; p<0.01)$, which suggested that spatially 
proximate clusters display a pronounced tendency to have similar levels of collective effervescence. To account for this spatial autocorrelation, the article followed Morenoff's (2003) suggestion to include a spatial lag of collective effervescence as a context-level covariate. This spatial lag, calculated using the spatial analysis tool GeoDA (Anselin, Syabri, and Kho 2006), captured the average value of the collective effervescence outcome in the neighboring area.

Finally, while the current article's statistical approach is frequentist in nature, the use of $p$ values is supplemented with Bayes factors that can quantify support for the null over the alternative hypothesis (Dienes 2014). Such assessment of evidence in favor of a non-association is not possible with $p$ values. Further, Bayes factors are more robust in separating genuine effects from false positives (RuízRuano García and Puga 2018), a feature that is particularly interesting given the exploratory approach of the article, which is prone to inflate the false-positive error rate. Specifically, the article reports Bayes factors approximated from the Bayesian information criterion (Hamaker et al. 2011; Wagenmakers 2007). This approximation is attractive because it is computationally simple and does not require the specification of priors. To evaluate the strength of the Bayes factor evidence, the following commonly used thresholds were applied (Jarosz and Wiley 2014; Jeffreys 1961): no evidence $(\sim 1)$, not worth more than a bare mention $(<3$ or $>1 / 3)$, substantial $(3$ or $1 / 3)$, strong $(10$ or $1 / 10)$, very strong $(30$ or $1 / 30)$, and decisive $(>100$ or $<1 / 100)$.

\section{Results}

Table 2 presents the estimated results of the exploratory multilevel regression model of collective effervescence. The focused interaction predictor was statistically significant at a 5 percent level, initially indicating that the level of socializing with the neighboring camp is associated with an elevated experience of collective effervescence. The Bayes factor, however, suggested that the evidence supporting this association is not worth more than a bare mention. Further adding to this fragile picture, the predictor displayed some instability across alternative modeling choices (see Steegen et al. [2016] and the supplemental material [osf.io/eqdgb] for examples).

Next, with respect to the compositional predictors, party preference was positively associated with the outcome, with a Bayes factor indicating substantial support for this finding. There was no association between gender and the collective effervescence outcome, with a Bayes factor suggesting that a non-association is approximately 16 times more probable than an association. Age and prior attendance were further found to be marginally statistically significant predictors, but the related Bayes factors offered more evidence for non-associations. Note, however, that these factors were so close to 1 that data overall are insensitive to detect effects or support for the null hypotheses. These reservations are further stressed by the circumstance that we here are assessing this relationship with multiple predictors and tests, inflating the risk of finding false positives by chance. Thus, when conservatively evaluating the compositional predictors with a Bonferroni corrected $p$ 
Table 2: Multilevel regression of collective effervescence.

\begin{tabular}{|c|c|c|c|c|}
\hline & $\begin{array}{c}\beta \\
\text { (Standard Error) }\end{array}$ & $\begin{array}{c}95 \% \\
\text { Confidence Interval }\end{array}$ & $p$ & $\begin{array}{l}\text { Bayes Factor } \\
\text { for } H_{0} \text { over } H_{1}\end{array}$ \\
\hline Focused interaction & $\begin{array}{c}0.18 \\
(0.07)\end{array}$ & 0.05 to 0.32 & 0.009 & 0.74 \\
\hline Party preference & $\begin{array}{c}0.26 \\
(0.08)\end{array}$ & 0.09 to 0.42 & 0.002 & 0.23 \\
\hline Male & $\begin{array}{c}-0.05 \\
(0.07)\end{array}$ & -0.18 to 0.09 & 0.476 & 16.80 \\
\hline Age & $\begin{array}{c}0.20 \\
(0.09)\end{array}$ & 0.02 to 0.37 & 0.026 & 1.89 \\
\hline Prior attendance & $\begin{array}{c}-0.03 \\
(0.01)\end{array}$ & -0.06 to -0.01 & 0.017 & 1.30 \\
\hline Social density & $\begin{array}{c}0.44 \\
(0.12)\end{array}$ & 0.20 to 0.68 & $<0.001$ & 0.08 \\
\hline Centrality & $\begin{array}{c}-0.31 \\
(0.13)\end{array}$ & -0.57 to -0.05 & 0.018 & 1.59 \\
\hline $\begin{array}{l}\text { Spatial lag of collective } \\
\text { effervescence }\end{array}$ & $\begin{array}{c}0.83 \\
(0.14)\end{array}$ & 0.55 to 1.11 & $<0.001$ & $<0.01$ \\
\hline Constant & $\begin{array}{c}-0.20 \\
(0.11)\end{array}$ & -0.41 to 0.02 & 0.074 & - \\
\hline
\end{tabular}

Note. $N=469$.

value at $\alpha=0.005$ (Benjamin et al. 2018; Sedgwick 2012), only party preference may be considered statistically significant.

The social density variable was statistically significant, with larger choice values (indexing high crowding) increasing the likelihood of a higher collective effervescence score. The related Bayes factor offered strong support for this association. By comparison, the spatial centrality predictor was only fragilely associated with the outcome, with a Bayes factor indicating data insensitivity in distinguishing the null hypothesis from the alternative.

Finally, the spatial lag of the collective effervescence was positively associated with the study outcome, with a Bayes factor offering very strong support for this association. Adding to this, this estimate clearly had the largest effect size of the included predictors, with a confidence interval suggesting that the collective effervescence outcome approximately increases between one-half and one standard deviation when the spatial lag variable increases by two standard deviations.

\section{Discussion}

The aim of the current study was to explore various plausible underpinnings of collective effervescence. Whereas the existing literature mainly highlights the importance of focused interaction, the current study also considered the potential influence of compositional and morphological/environmental factors. The multilevel regression analysis indicates that focused interaction has only a fragile 
positive association with the collective effervescence outcome. However, it should be noted that the direction of the estimated effect is what should be expected from the existing body of evidence, suggesting that focused interactions promote positive collective emotions (Heider and Warner 2010; Rossner 2011; Thye et al. 2014; Wellman, Corcoran, and Stockly-Meyerdirk 2014).

The analysis further indicates that compositional properties play some role in shaping the collective effervescence phenomenon. This is most convincingly evidenced by the finding that a high level of party preference has a moderately robust association with collective effervescence. By comparison, gender was not associated with collective effervescence, and data were insensitive to establish whether age and prior attendance are associated with the outcome or not. Taken together, these findings support the view, appreciated by Collins's (2004) IR theory, that compositional features should not be rejected when accounting for collective effervescence and micro-social processes. More broadly, this argument aligns with the growing insight that micro-sociology (Smith 2015) and social psychology (Swann and Jetten 2017) have overemphasized the "power of the situation" at the expense of person-based influences and person-situation interactions (Fleeson and Noftle 2008).

Finally, the analysis supports the relationship between social-morphological densities and emotional excitement. This finding highlights that collective effervescence is not merely promoted by focused interaction processes, as the Durkheimian tradition often assumes; also, and sometimes to a greater extent, collective effervescence may be associated with unfocused interaction dynamics unfolding within a crowd of people. On this point, Collins's IR theory is a rare attempt to theorize such a micro-morphological underpinning of collective effervescence: "Being in a crowd gives some sense of being 'where the action is,' even if you personally are not part of any well-defined action" (Collins 2004:82). By linking social densities with positive emotions, Collins and the current study pose a counterweight to the influential assumption that high densities promote adverse social outcomes, including negatively valenced emotions (Boyko and Cooper 2011). As such, the findings of this study align with Freedman's (1975:105) suggestion that "[c]rowding is not generally negative and it does intensify reactions to other people."

The above morphological considerations, moreover, pave the way for the more far-reaching suggestion that architectural space holds a "real agency" (Hillier 2005); this may concentrate movement flows in spatially integrated places and thus, in turn, facilitate the excited feeling of being in a crowd (Liebst 2015, 2016). That such an emotional dynamic may be shaped by the spatial network itself, independently from other social-morphological features (Ratti 2004), is further substantiated by the finding that spatial centrality was not robustly associated with collective effervescence.

The above interpretations diverge from the mainstream Durkheimian perspective, also shared by Collins (1983:187), that "time, space, and numbers do not do anything; all real causal forces must come from human beings acting in some situation." As such, the agency of morphological space indicated in the current article counters the criticism that a Durkheimian approach is irreconcilable with an understanding of non-human agency (Latour 1996). This position also invites 
Durkheimian scholars to revisit the often neglected attempts to theorize morphological agency within the tradition (Hillier et al. 1987; Liebst 2016; Lindemann 2011; Mauss 1979).

The spatial lag of the collective effervescence outcome was found to be robustly and strongly associated with collective effervescence. This finding suggests that collective effervescence, similar to other social phenomena (Logan 2012; Weisburd 2015), displays a pronounced spatial clustering tendency, an observation that is also supported by the very large intraclass correlation reported above. Moreover, spatial lags are often interpreted as suggesting some "spillover effect" between places (Anselin 2002). As such, the spatial lag in the current model may indicate that adjacent locations affect one another's excitement levels and that such sociospatial influences further intensify the hot spots of collective effervescence.

Besides being relevant for Durkheimian research, the approach and results of the current study are also informative for the field of festival-event studies. In a review of this field of study, Getz (2010:20) stresses that an adequate understanding of festival experiences should be rooted in the sociological and anthropological disciplines, yet there is "little evidence in the research literature (and in the pertinent textbooks) that the connections are being made." The current study addresses this concern by offering a sociological Durkheimian understanding of the sources of emotionally effervescent festival experiences. Thus, besides adding to the growing knowledge that festival experiences are clustered in hot spots (Pettersson and Getz 2009) and are positively associated with event crowding (Kim, Lee, and Sirgy 2016), the current study also provides a social-morphological framework in which to interpret these findings.

The present study has limitations that warrant discussion. Although a distinction between interactional, compositional, and morphological influences may be theoretically helpful, these factors often overlap and are hard to disentangle in practice (Manski 1993). Regarding this concern, it is known that multilevel model assessments of context effects, such as the morphological density factor in the current study, cannot be fully separated from the compositional effects of self-selection (Oakes 2004). Hence, it is plausible that a proportion of the relatively large social density effect may in fact be attributed to unmeasured compositional effects. Similarly, it is likely that the direct crowding-experience relationship assumed in the current article is confounded by the individuals' perceptual expectation that some places and social activities are more exciting than others (Goffman 1974; Sampson and Raudenbush 2004).

Another limitation concerns the reliance on survey self-reports in the operationalization of the collective effervescence outcome and, most problematically, the study subjects' behavioral engagement in focused interactions. First, like other emotional phenomena, collective effervescence may be expected to have physiological, behavioral, and experiential dimensions (de Gelder 2009; Mauss and Robinson 2009; Xygalatas et al. 2011); yet, it is only the latter dimension that is captured by the included self-reported measure. Second, by measuring interactional behavior with survey self-reports, the current study makes itself vulnerable to the critique that human behavior should ideally be observed directly, given that self-reported accounts are notorious for providing an unreliable picture of how people actually 
behave (Baumeister, Vohs, and Funder 2007; Reiss 1991). The inclusion of an indirect and therefore noisy measurement of focused interaction may, in part, explain the fragile association between this factor and collective effervescence.

Finally, the limitations of the article's exploratory approach are highlighted. Although exploratory data analysis is a valuable and legitimate approach if disclosed (Tukey 1980; Wicherts et al. 2016), it should be acknowledged that it inflates the risk of reporting false positives (Forstmeier, Wagenmakers, and Parker 2017). Conservatively interpreted Bayes factors were reported in parallel to $p$ values as a countermeasure to this issue. Bayes factors are still atypical within sociological research, and I hope the current study will serve as an illustration of the relevance of reporting Bayes factors as a means of moving beyond the binary view of statistical inferences promoted by $p$ values (Cumming 2014). However, regardless of this Bayesian approach, strictly confirmatory research is needed to assess the robustness of the correlates of collective effervescence identified in this study.

\section{References}

Alexander, Jeffrey C. 2005. “The Inner Development of Durkheim's Sociological Theory: From Early Writings to Maturity." Pp. 136-59 in The Cambridge Companion to Durkheim, edited by J. C. Alexander and P. Smith. Cambridge, UK: Cambridge University Press. https://doi.org/10.1017/CCOL9780521806725.006.

Anselin, Luc. 2002. "Under the Hood Issues in the Specification and Interpretation of Spatial Regression Models." Agricultural Economics 27:247-67. https://doi.org/10.1111/j . 1574-0862.2002.tb00120.x.

Anselin, Luc, Ibnu Syabri, and Youngihn Kho. 2006. "GeoDa: An Introduction to Spatial Data Analysis." Geographical Analysis 38:5-22. https://doi .org/10.1111/j.0016-7363. 2005.00671.x.

Baumeister, Roy F., Kathleen D. Vohs, and David C. Funder. 2007. “Psychology As the Science of Self-Reports and Finger Movements: Whatever Happened to Actual Behavior?" Perspectives on Psychological Science 2:396-403. https : //doi . org/10.1111/j.1745-6916. 2007.00051.x.

Benjamin, Daniel J., James O. Berger, Magnus Johannesson, Brian A. Nosek, Eric-Jan Wagenmakers, Richard Berk, Kenneth A. Bollen, Björn Brembs, Lawrence Brown, and Colin Camerer. 2018. "Redefine Statistical Significance." Nature Human Behaviour 2:6-10. https://doi.org/10.1038/s41562-017-0189-z.

Boyko, Christopher T., and Rachel Cooper. 2011. "Clarifying and Re-Conceptualising Density." Progress in Planning 76:1-61. https://doi.org/10.1016/j.progress. 2011. 07.001.

Buehler, Arthur. 2012. “The Twenty-First-Century Study of Collective Effervescence: Expanding the Context of Fieldwork." Fieldwork in Religion 7:70-97. https://doi . org/10. 1558/firn.v7i1.70.

Burgess, Ernest W. 1925. “The Growth of the City." Pp. 47-62 in The City, edited by R. E. Park. Chicago, IL: University of Chicago Press.

Collins, Randall. 1981. "On the Microfoundations of Macrosociology." American Journal of Sociology 86:984-1014. https://doi.org/10.1086/227351.

Collins, Randall. 1983. "Micromethods As a Basis for Macrosociology." Journal of Contemporary Ethnography 12:184-202. https://doi .org/10.1177/0098303983012002004. 
Collins, Randall. 1989. "Sociology: Proscience or Antiscience?" American Sociological Review 54:124-39. https://doi.org/10.2307/2095666.

Collins, Randall. 1993. "Emotional Energy As the Common Denominator of Rational Action." Rationality and Society 5:203-30. https://doi .org/10.1177/1043463193005002005.

Collins, Randall. 1994. Four Sociological Traditions. Oxford, UK: Oxford University Press.

Collins, Randall. 2004. Interaction Ritual Chains. Princeton, NJ: Princeton University Press. https://doi.org/10.1515/9781400851744.

Collins, Randall. 2005. "The Durkheimian Movement in France and in World Sociology." Pp. 101-35 in The Cambridge Companion to Durkheim, edited by J. C. Alexander and P. Smith. Cambridge, UK: Cambridge University Press. https://doi.org/10.1017/ CCOL9780521806725.005.

Collins, Randall. 2007. "The Classical Tradition in Sociology of Religion." Pp. 19-38 in The Sage Handbook of the Sociology of Religion, edited by J. A. Beckford and J. Demerath. London, UK: Sage. https://doi .org/10.4135/9781848607965.n2.

Cumming, Geoff. 2014. "The New Statistics: Why and How." Psychological Science 25:7-29. https://doi .org/10.1177/0956797613504966.

de Gelder, Beatrice. 2009. "Why Bodies? Twelve Reasons for Including Bodily Expressions in Affective Neuroscience." Philosophical Transactions of the Royal Society B: Biological Sciences 364:3475-84. https://doi.org/10.1098/rstb.2009.0190.

Dienes, Zoltan. 2014. “Using Bayes to Get the Most out of Non-Significant Results." Frontiers in Psychology 5:1-17. https://doi.org/10.3389/fpsyg. 2014.00781.

DiMaggio, Paul, Clark Bernier, Charles Heckscher, and David Mimno. 2018. "Interaction Ritual Threads: Does IRC Theory Apply Online?" Pp. 99-142 in Ritual, Emotion, Violence, edited by E. B. Weininger, A. Lareau, and O. Lizardo. London, UK: Routledge. https : //doi.org/10.4324/9780429464157-4.

Durkheim, Émile. 1982. The Rules of Sociological Method and Selected Texts on Sociology and Its Method. New York, NY: The Free Press. https://doi.org/10.1007/ 978-1-349-16939-9.

Durkheim, Émile. 1994. “Note on Social Morphology." Pp. 88-90 in Emile Durkheim: On Institutional Analysis, edited by M. Traugott. Chicago, IL: University of Chicago Press.

Durkheim, Émile. [1912] 1995. The Elementary Forms of the Religious Life. New York, NY: The Free Press.

Fleeson, William, and Erik Noftle. 2008. "The End of the Person-Situation Debate: An Emerging Synthesis in the Answer to the Consistency Question." Social and Personality Psychology Compass 2:1667-84. https : //doi .org/10.1111/j.1751-9004.2008.00122 .x.

Forstmeier, Wolfgang, Eric-Jan Wagenmakers, and Timothy H. Parker. 2017. “Detecting and Avoiding Likely False-Positive Findings-A Practical Guide." Biological Reviews 92:1941-68. https://doi.org/10.1111/brv. 12315.

Freedman, Jonathan L. 1975. Crowding and Behavior. New York, NY: W. H. Freeman.

Freeman, Linton C. 1977. "A Set of Measures of Centrality Based on Betweenness." Sociometry 40:35-41. https://doi.org/10.2307/3033543.

Gelman, Andrew. 2008. "Scaling Regression Inputs by Dividing by Two Standard Deviations." Statistics in Medicine 27:2865-73. https ://doi.org/10.1002/sim.3107.

Getz, Donald. 2010. “The Nature and Scope of Festival Studies." International Journal of Event Management Research 5:1-47.

Goffman, Erving. 1963. Behavior in Public Places: Notes on the Social Organization of Gatherings. New York, NY: Free Press of Glencoe. 
Goffman, Erving. 1967. Interaction Ritual: Essays on Face-to-Face Interaction. Oxford, UK: Aldine.

Goffman, Erving. 1974. Frame Analysis: An Essay on the Organization of Experience. Cambridge, MA: Harvard University Press.

Greetham, Danica Vukadinović, Abhijit Sengupta, Robert Hurling, and Joy Wilkinson. 2015. "Interventions in Social Networks: Impact on Mood and Network Dynamics." Advances in Complex Systems 18:1550016. https://doi .org/10.1142/S0219525915500162.

Griffiths, Sam. 2014. “Space Syntax As Interdisciplinary Urban Design Pedagogy." Pp. 158-67 in Explorations in Urban Design: An Urban Design Research Primer, edited by M. Carmona. Farnham, UK: Ashgate Publishing.

Hamaker, Ellen L., Pascal van Hattum, Rebecca M. Kuiper, and Herbert Hoijtink. 2011. "Model Selection Based on Information Criteria in Multilevel Modeling." Pp. 231-55 in Handbook for Advanced Multilevel Analysis, edited by J. J. Hox and J. K. Roberts. New York, NY: Routledge and Taylor and Francis Group.

Hedström, Peter. 2005. Dissecting the Social: On the Principles of Analytical Sociology. Cambridge, UK: Cambridge University Press. https://doi.org/10.1017/ CB09780511488801.

Heider, Anne, and R. Stephen Warner. 2010. "Bodies in Sync: Interaction Ritual Theory Applied to Sacred Harp Singing." Sociology of Religion 71:76-97. https : //doi .org/10. 1093/socrel/srq001.

Heinskou, Marie B., and Lasse S. Liebst. 2016. “On the Elementary Neural Forms of Micro-Interactional Rituals: Integrating Autonomic Nervous System Functioning into Interaction Ritual Theory." Sociological Forum 31:354-76. https://doi.org/10.1111/ socf. 12248.

Hillier, Bill 2005. "Between Social Physics and Phenomenology." Pp. 3-23 in Proceedings of the 5th International Symposium on Space Syntax, edited by A. van Nes. Delft, Netherlands: Techne Press.

Hillier, Bill, and Julienne Hanson. 1984. The Social Logic of Space. Cambridge, UK: Cambridge University Press. https://doi.org/10.1017/CB09780511597237.

Hillier, Bill, and Noah Raford. 2010. "Description and Discovery in Socio-Spatial Analysis: The Case of Space Syntax." Pp. 265-82 in The Sage Handbook of Measurement, edited by G. Walford, E. Tucker, and M. Viswanathan. London, UK: Sage Publications. https : //doi.org/10.4135/9781446268230.n14.

Hillier, Bill, Richard Burdett, John Peponis, and Alan Penn. 1987. “Creating Life: Or, Does Architecture Determine Anything?" Architecture and Behaviour 3:233-50.

Hillier, Bill, and Shinichi Iida. 2005. "Network and Psychological Effects in Urban Movement." Pp. 475-90 in Proceedings of Spatial Information Theory: International Conference, COSIT, edited by A. G. Cohn and D. M. Mark. Ellicottsville, NY: Springer. https ://doi .org/10 . 1007/11556114_30.

Hox, Joop J., Mirjam Moerbeek, and Rens van de Schoot. 2017. Multilevel Analysis: Techniques and Applications. London, UK: Routledge. https://doi .org/10.4324/9781315650982.

Jarosz, Andrew F., and Jennifer Wiley. 2014. "What Are the Odds? A Practical Guide to Computing and Reporting Bayes Factors." The Journal of Problem Solving 7:2. https: //doi.org/10.7771/1932-6246.1167.

Jeffreys, Harold. 1961. Theory of Probability. Oxford, UK: Oxford University.

Kearney, Matthew. 2018. "Totally Alive: The Wisconsin Uprising and the Source of Collective Effervescence." Theory and Society 47:233-54. https://doi.org/10.1007/ s11186-018-9312-z. 
Kim, Dohee, Choong-Ki Lee, and M. Joseph Sirgy. 2016. “Examining the Differential Impact of Human Crowding Versus Spatial Crowding on Visitor Satisfaction at a Festival." Journal of Travel and Tourism Marketing 33:293-312. https: //doi .org/10 . 1080/10548408. 2015.1024914.

Latour, Bruno. 1996. "On Interobjectivity." Mind, Culture, and Activity 3:228-45. https: //doi.org/10.1207/s15327884mca0304_2.

Liebst, Lasse S. 2015. "Phenomenology of the Movement Economy: A Multilevel Analysis." The Journal of Space Syntax 6:49-60.

Liebst, Lasse S. 2016. “Reassembling Durkheimian Sociology of Space.” Pp. 214-24 in Spatial Cultures: Towards a New Social Morphology of Cities Past and Present, edited by S. Griffiths and A. von Lünen. New York, NY: Routledge.

Lindemann, Gesa. 2011. "On Latour's Social Theory and Theory of Society, and His Contribution to Saving the World." Human Studies 34:93-110. https://doi .org/10.1007/ s10746-011-9178-9.

Logan, John R. 2012. "Making a Place for Space: Spatial Thinking in Social Science." Annual Review of Sociology 38:507-24. https://doi.org/10.1146/ annurev-soc-071811-145531.

Manski, Charles F. 1993. "Identification of Endogenous Social Effects: The Reflection Problem." The Review of Economic Studies 60:531-42. https : //doi . org/10. 2307/2298123.

Mauss, Iris B., and Michael D. Robinson. 2009. “Measures of Emotion: A Review.” Cognition and Emotion 23:209-37. https://doi .org/10.1080/02699930802204677.

Mauss, Marcel. [1906] 1979. Seasonal Variations of the Eskimo: A Study in Social Morphology. London, UK: Routledge and Kegan Poul.

McNeish, Daniel M., and Laura M. Stapleton. 2016. "The Effect of Small Sample Size on Two-Level Model Estimates: A Review and Illustration." Educational Psychology Review 28:295-314. https://doi .org/10.1007/s10648-014-9287-x.

McPherson, Miller, Lynn Smith-Lovin, and James M. Cook. 2001. “Birds of a Feather: Homophily in Social Networks." Annual Review of Sociology 27:415-44. https://doi. org/10.1146/annurev.soc.27.1.415.

Mogan, Reneeta, Ronald Fischer, and Joseph A. Bulbulia. 2017. "To Be in Synchrony or Not? A Meta-analysis of Synchrony's Effects on Behavior, Perception, Cognition and Affect." Journal of Experimental Social Psychology 72:13-20. https://doi.org/10.1016/j . jesp. 2017.03 .009$.

Morenoff, Jeffrey D. 2003. "Neighborhood Mechanisms and the Spatial Dynamics of Birth Weight." American Journal of Sociology 108:976-1017. https ://doi .org/10 .1086/374405.

Musca, Serban C., Rodolphe Kamiejski, Armelle Nugier, Alain Méot, Abdelatif Er-Rafiy, and Markus Brauer. 2011. “Data with Hierarchical Structure: Impact of Intraclass Correlation and Sample Size on Type-I Error." Frontiers in Psychology 2:74. https://doi.org/10. 3389/fpsyg. 2011.00074.

Niekrenz, Yvonne. 2014. "The Elementary Forms of Carnival: Collective Effervescence in Germany's Rhineland." Canadian Journal of Sociology 39:643-66.

Oakes, J. Michael. 2004. “The (Mis)Estimation of Neighborhood Effects: Causal Inference for a Practicable Social Epidemiology." Social Science and Medicine 58:1929-52. https : //doi.org/10.1016/j.socscimed.2003.08.004.

Park, Robert E. 1939. "Notes on the Origin of the Society for Social Research." Regenstein Library Special Collections, Wirth Papers, Box 36, Folder 1. University of Chicago. 
Pedersen, Kristine Munkgård. 2014. “Roskilde Festival: Et Socio-Æstetisk Landskab.” Kultur og Klasse 42:113-24. https: //doi .org/10.7146/kok.v42i118.19839.

Pettersson, Robert, and Donald Getz. 2009. "Event Experiences in Time and Space: A Study of Visitors to the 2007 World Alpine Ski Championships in Åre, Sweden." Scandinavian Journal of Hospitality and Tourism 9:308-26. https : //doi . org/10.1080/15022250903119504.

Pickering, William S. F. 1984. Durkheim's Sociology of Religion: Themes and Theories. London, UK: Routledge.

Rankin, Catharine H., Thomas Abrams, Robert J. Barry, Seema Bhatnagar, David F. Clayton, John Colombo, Gianluca Coppola, Mark A. Geyer, David L. Glanzman, and Stephen Marsland. 2009. "Habituation Revisited: An Updated and Revised Description of the Behavioral Characteristics of Habituation." Neurobiology of Learning and Memory 92:135-8. https://doi.org/10.1016/j.nlm.2008.09.012.

Ratti, Carlo. 2004. "Space Syntax: Some Inconsistencies." Environment and Planning B: Planning and Design 31:487-99. https://doi .org/10.1068/b3019.

Reiss, Jr, Albert J. 1991. “The Trained Incapacities of Sociologists.” Pp. 297-315 in Sociology and Its Publics, edited by T. C. Halliday and M. Janowitz. Chicago, IL: University of Chicago Press.

Rossner, Meredith. 2011. "Emotions and Interaction Ritual: A Micro-Analysis of Restorative Justice." The British Journal of Criminology 51:95-119. https://doi .org/10.1093/bjc/ azq075.

Ruíz-Ruano García, Ana M., and Jorge L. Puga. 2018. “Deciding on Null Hypotheses Using P-Values or Bayesian Alternatives: A Simulation Study." Psicothema 30:110-5.

Sampson, Robert J., and Stephen W. Raudenbush. 2004. “Seeing Disorder: Neighborhood Stigma and the Social Construction of 'Broken Windows."' Social Psychology Quarterly 67:319-42. https://doi.org/10.1177/019027250406700401.

Sedgwick, Philip. 2012. "Multiple Significance Tests: The Bonferroni Correction." BMJ 344:e509. https://doi .org/10.1136/bmj . e509.

Sharmin, Samia, and Md Kamruzzaman. 2018. "Meta-analysis of the Relationships between Space Syntax Measures and Pedestrian Movement." Transport Reviews 38:524-50. https : //doi.org/10.1080/01441647.2017.1365101.

Smith, Christian. 2015. To Flourish or Destruct: A Personalist Theory of Human Goods, Motivations, Failure, and Evil. Chicago, IL: University of Chicago Press. https ://doi .org/10. 7208/chicago/9780226232003.001.0001.

Snizek, Bernhard, Thomas A. S. Nielsen, and Hans Skov-Petersen. 2013. "Mapping Bicyclists' Experiences in Copenhagen." Journal of Transport Geography 30:227-33. https://doi . org/10.1016/j.jtrangeo.2013.02.001.

Ståhle, Alexander, Lars Marcus, and Anders Karlström. 2005. “Place Syntax: Geographic Accessibility with Axial Lines in Gis." Pp. 131-44 in Proceedings of the 5th International Symposium on Space Syntax, edited by A. van Nes. Delft, Netherlands: Techne Press.

Steegen, Sara, Francis Tuerlinckx, Andrew Gelman, and Wolf Vanpaemel. 2016. "Increasing Transparency through a Multiverse Analysis." Perspectives on Psychological Science 11:70212. https://doi .org/10.1177/1745691616658637.

Swann, Jr, William B., and Jolanda Jetten. 2017. "Restoring Agency to the Human Actor." Perspectives on Psychological Science 12:382-99. https://doi.org/10.1177/ 1745691616679464.

Swann, Jr, William B., Jolanda Jetten, Ángel Gómez, Harvey Whitehouse, and Brock Bastian. 2012. "When Group Membership Gets Personal: A Theory of Identity Fusion." Psychological Review 119:441-56. https://doi .org/10.1037/a0028589. 
Thye, Shane R., Aaron Vincent, Edward J. Lawler, and Jeongkoo Yoon. 2014. "Relational Cohesion, Social Commitments, and Person-to-Group Ties: Twenty-Five Years of a Theoretical Research Program." Pp. 99-138 in Advances in Group Processes, edited by in S. R. Thye and E. J. Lawler. Bingley, UK: Emerald Group Publishing Limited. https: //doi.org/10.1108/S0882-614520140000031008.

Tukey, John W. 1980. “We Need Both Exploratory and Confirmatory.” The American Statistician 34:23-25.

Turner, Alasdair. 2001. "Angular Analysis." Pp. 30.1-11 in Proceedings of the 3rd International Symposium on Space Syntax, edited by J. Peponis, J. Wineman, and S. Bafna. Atlanta, GA: Georgia Institute of Technology.

Turner, Alasdair. 2004. “Depthmap 4: A Researcher's Handbook.” London, UK: University College London Bartlett School of Graduate Studies. Retrieved December 12, 2018 (discovery.ucl.ac.uk/2651).

Turner, Jonathan H. 2010. Theoretical Principles of Sociology, Volume 3: Microdynamics. London, UK: Routledge.

von Scheve, Christian. 2011. “Collective Emotions in Rituals: Elicitation, Transmission, and a 'Matthew-Effect."' Pp. 55-77 in Emotions in Rituals, edited A. Michaels and C. Wulf. London, UK: Routledge.

Wagenmakers, Eric-Jan. 2007. "A Practical Solution to the Pervasive Problems of P Values." Psychonomic Bulletin and Review 14:779-804. https://doi .org/10.3758/BF03194105.

Weisburd, David. 2015. "The Law of Crime Concentration and the Criminology of Place." Criminology 53:133-57. https://doi .org/10.1111/1745-9125.12070.

Wellman, James K., Katie E. Corcoran, and Kate Stockly-Meyerdirk. 2014. "'God Is Like a Drug...': Explaining Interaction Ritual Chains in American Megachurches." Sociological Forum 29:650-72. https://doi .org/10.1111/socf . 12108.

Wicherts, Jelte M., Coosje L. S. Veldkamp, Hilde E. M. Augusteijn, Marjan Bakker, Robbie van Aert, and Marcel A. L. M. van Assen. 2016. "Degrees of Freedom in Planning, Running, Analyzing, and Reporting Psychological Studies: A Checklist to Avoid P-Hacking." Frontiers in Psychology 7:1832. https://doi .org/10.3389/fpsyg. 2016.01832.

Wilsnack, Richard W., Nancy D. Vogeltanz, Sharon C. Wilsnack, and T. Robert Harris. 2000. "Gender Differences in Alcohol Consumption and Adverse Drinking Consequences: Cross-Cultural Patterns." Addiction 95:251-65. https://doi.org/10.1046/ j.1360-0443.2000.95225112.x.

Wrong, Dennis H. 1961. "The Oversocialized Conception of Man in Modern Sociology." American Sociological Review 26:183-93. https : //doi .org/10.2307/2089854.

Xygalatas, Dimitris, Ivana Konvalinka, Joseph Bulbulia, and Andreas Roepstorff. 2011. "Quantifying Collective Effervescence: Heart-Rate Dynamics at a Fire-Walking Ritual." Communicative and Integrative Biology 4:735-8. https://doi .org/10.4161/cib.17609.

Acknowledgments: The author would like to thank the following individuals for their comments and suggestions: Randall Collins, Line Vistisen Liebst, Inge Kryger Pedersen, and Richard Philpot.

Lasse Suonperä Liebst: Department of Sociology, University of Copenhagen. E-mail: lsl@soc.ku.dk. 